\title{
Astroglial Plasticity in the Hippocampus is Affected by Chronic Psychosocial Stress and Concomitant Fluoxetine Treatment
}

\author{
Boldizsár Czéh*,', Mária Simon', Barthel Schmelting', Christoph Hiemke² and Eberhard Fuchs 1,3 \\ 'Clinical Neurobiology Laboratory, German Primate Center, Göttingen, Germany; ²Department of Psychiatry, University of Mainz, Mainz, \\ Germany; ${ }^{3}$ Department of Neurology, Medical School, University of Göttingen, Göttingen, Germany
}

\begin{abstract}
Analysis of post-mortem tissue from patients with affective disorders has revealed a decreased number of glial cells in several brain areas. Here, we examined whether long-term psychosocial stress influences the number and morphology of hippocampal astrocytes in an animal model with high validity for research on the pathophysiology of major depression. Adult male tree shrews were submitted to 5 weeks of psychosocial stress, after which immunocytochemical and quantitative stereological techniques were used to estimate the total number and somal volume of glial fibrillary acidic protein-positive astrocytes in the hippocampal formation. Stress significantly decreased both the number $(-25 \%)$ and somal volume $(-25 \%)$ of astroglia, effects that correlated notably with the stress-induced hippocampal volume reduction. Additionally, we examined whether antidepressant treatment with fluoxetine, a selective serotonin reuptake inhibitor, offered protection from these stress-induced effects. Animals were subjected to 7 days of psychosocial stress before the onset of daily oral administration of fluoxetine ( $15 \mathrm{mg} / \mathrm{kg}$ per day), with stress continued throughout the 28-day treatment period. Fluoxetine treatment prevented the stress-induced numerical decrease of astrocytes, but had no counteracting effect on somal volume shrinkage. In nonstressed animals, fluoxetine treatment had no effect on the number of astrocytes, but stress exposure significantly reduced their somal volumes (-20\%). These notable changes of astroglial structural plasticity in response to stress and antidepressant treatment support the notion that glial changes may contribute to the pathophysiology of affective disorders as well as to the cellular actions of antidepressants.
\end{abstract}

Neuropsychopharmacology (2006) 31, I6I6- 1626. doi:I 0.1038/sj.npp. I 300982; published online I 4 December 2005

Keywords: glia; astrocyte; cell number; stereology; antidepressant; hippocampal volume

\section{INTRODUCTION}

Affective disorders are common and life-threatening illnesses, but despite extensive investigations, little is known about the underlying fundamental biology (Nestler et al, 2002). Recently, several in vivo imaging studies revealed that both the hippocampus and prefrontal cortex undergo selective volume reduction in several stress-related neuropsychiatric illnesses, particularly in major depressive disorder; the exact cellular basis for this volume decrease, however, has not yet been elucidated (Drevets, 2000; Manji and Duman, 2001; Bremner, 2002; Manji et al, 2003; Sheline, 2003). Post-mortem histological analysis of the frontal cortex demonstrated a decreased number of glia in patients suffering from major depressive disorder (Öngür et al, 1998; Rajkowska et al, 1999; Cotter et al, 2001a, 2002),

*Correspondence: Dr B Czéh, Clinical Neurobiology Laboratory, German Primate Center, Kellnerweg 4, 37077 Göttingen, Germany, Tel: + 49 55। 385 I I34, Fax: + 4955 I 385। 307,

E-mail: bczeh@dpz.gwdg.de

Received 27 June 2005; revised 21 September 2005; accepted 18 October 2005

Online publication: 25 October 2005 at http://www.acnp.org/citations/ Npp I02505050420/default.pdf and reduced glial density and glia/neuron ratio has been reported in the amygdala as well (Bowley et al, 2002; Hamidi et al, 2004). These and other observations led to the hypothesis that glial cell dysfunction may contribute to the pathogenesis of affective disorders (Coyle and Schwarcz, 2000; Cotter et al, 2001b).

In the hippocampus, no histopathological studies have so far demonstrated any significant loss of glial cells or neurons in the brains of patients suffering from major depression (Lucassen et al, 2001; Müller et al, 2001; Stockmeier et al, 2004). However, this negative finding might be due to the fact that all these studies were based on a small sample size and none of them used an unbiased counting method, most probably because the investigators did not have access to the complete, intact brain structure of interest (ie the hippocampal formation), an essential requirement for proper stereology. Thus, at this point one cannot rule out the possibility that future more systematic studies may reveal alterations in the number of neurons or glia, especially if specific subpopulation of cells are in focus of the analysis.

Among the most potent factors known to trigger or induce major depressive episodes are stressful life events (Kendler et al, 1999). This stress hypothesis of mood 
disorders has stimulated the development of a number of putative animal models that simulate or model aspects of depression by manipulating, for example, social relationships. In humans, loss of rank or social status is an example of the more general class of loss events (which are increasingly recognized as a specific type of 'life event') that are associated with a greater risk of depression (Brown, 1993). Using similar psychosocial perturbations as chronic stressors, powerful animal models for depression have been established. In recent years, our group has provided increasing evidence that chronic psychosocial conflict in the male tree shrew, Tupaia belangeri, represents a natural and valid paradigm for studying the behavioral, endocrine, and neurobiological changes that may underlie stress-related disorders such as major depression (Fuchs and Flugge, 2002; Fuchs et al, 2004).

To our knowledge, no systematic cell counting study has examined in experimental animals, the possibility of changes in glial cell numbers as a result of chronic stress. To answer this question, we investigated whether long-term psychosocial stress could affect the number and morphology of glial fibrillary acidic protein (GFAP) immunoreactive astrocytes in the hippocampal formation, using the chronic psychosocial stress paradigm in the male tree shrew. We focused on astroglia because of the growing number of data indicating that the role of astrocytes in function of the central nervous system so far has been considerably underestimated (Fields and Stevens-Graham, 2002). Additionally, we examined whether treatment with the antidepressant fluoxetine, a selective serotonin reuptake inhibitor (SSRI) with well-known clinical efficacy (Stokes and Holtz, 1997), offers protection from possible stressinduced morphological alterations. This approach was based on recent clinical and preclinical findings, which suggest that depressive disorders may be associated with an impairment of structural plasticity and cellular resilience, and that antidepressant medications may correct this dysfunction (Manji and Duman, 2001; Manji et al, 2000, $2001,2003)$. Indeed, several studies have demonstrated that treatment with various classes of antidepressants can reverse both the functional impairments and the structural alterations of the hippocampal formation induced by stress (Watanabe et al, 1992; Czéh et al, 2001, 2005b; Malberg and Duman, 2003; Vermetten et al, 2003; Alonso et al, 2004; Lucassen et al, 2004).

\section{MATERIALS AND METHODS}

\section{Animals, Experimental Procedure, and Fluoxetine Treatment}

For the experiments, we used the tree shrew, Tupaia belangeri, a species phylogenetically close to primates (Martin, 1990). We decided to investigate these animals because they are well suited for a chronic stress paradigm (Fuchs and Flugge, 2002). Experimentally naive adult male tree shrews ( $n=22$; mean age $9 \pm 1$ months) were obtained from the breeding colony at the German Primate Center (Göttingen, Germany). Animals were housed individually on a $12 \mathrm{~h}$ light $12 \mathrm{~h}$ dark cycle with ad libitum access to food and water (Fuchs, 1999). All animal experiments were in accordance with the European Communities Council
Directive of 24 November 1986, (86/EEC), with the US National Institutes of Health Guide for the Care and Use of Laboratory Animals, and were approved by the Government of Lower Saxony, Germany. The minimum number of animals required to obtain consistent data was used.

Experimental design. As depicted in Figure 1a, animals were divided into four experimental groups: Control $(n=6)$, Control + Fluoxetine $(n=6)$, Stress $(n=5)$, and Stress + Fluoxetine $(n=5)$. The experiment consisted of two phases and lasted for 5 weeks ( 35 days). The first experimental phase ('Stress') lasted 7 days, during which the animals of the Stress and the Stress + Fluoxetine group were submitted to daily psychosocial conflict. The psychosocial stress procedure was carried out according to our standard protocol (for details see Czéh et al, 2001, 2005a,b). The second experimental phase consisted of the fluoxetine treatment for 4 weeks (28 days), while animals remained in the psychosocial conflict situation.

Animals of the Control + Fluoxetine and Stress + Fluoxetine groups received the compound $(15 \mathrm{mg} / \mathrm{kg}$ body weight

\begin{tabular}{|c|c|c|}
\hline $\mathbf{a}$ & \multicolumn{2}{|c|}{ Experimental Procedures } \\
\hline Control $\longrightarrow$ & \multicolumn{2}{|r|}{ No Stress } \\
\hline $\begin{array}{l}\text { Control + } \\
\text { Fluoxetine }\end{array}$ & No Stress & Fluoxetine \\
\hline Stress & \multicolumn{2}{|r|}{ Stress } \\
\hline \multirow{2}{*}{$\begin{array}{l}\text { Stress + } \\
\text { Fluoxetine }\end{array}$} & Stress & Stress + Fluoxetine \\
\hline & 7 days & 28 days \\
\hline
\end{tabular}

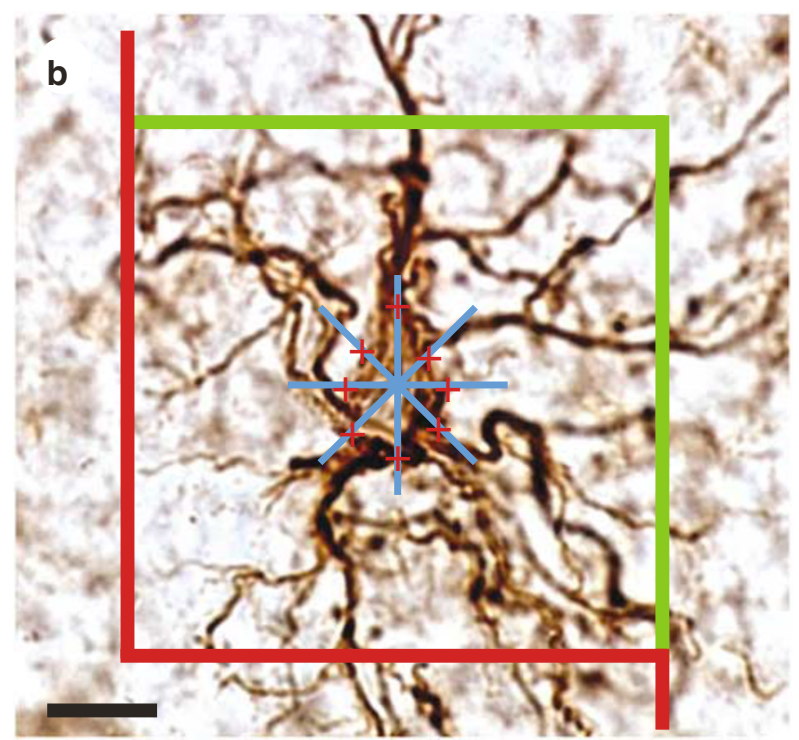

Figure I (a) Experimental groups and design. For details, see the Materials and methods. (b) Light micrograph illustrating the stereological counting frame. In the center is one astrocyte from a control CAI stratum radiatum area. Only cells that lay within the volume $(50 \times 50 \times 20 \mu \mathrm{m})$ of the frame or touched the green lines were counted; those that crossed the red lines were excluded from the analysis. Estimates of cell size were generated using the nucleator probe (blue lines). For each cell, eight isotropic lines converged on the nucleus and intersected the somal boundary. Scale bar, $10 \mu \mathrm{m}$. 
(BW) per day) orally in the morning between 0800 and 0815. The drug, Fluoxetin ratiopharm $(4 \mathrm{mg} / \mathrm{ml}$ oral solution; Ratiopharm GmbH, Ulm, Germany), was administered via a bulb-headed cannula into the buccal cavity, and the animals were allowed to swallow the solution. Animals of the Control and Stress groups were treated with vehicle only. Animals received the drug orally because this is the most common route of antidepressant administration in psychiatric patients.

We conducted a pilot study to establish the necessary dosage of fluoxetine. Adult male tree shrews $(n=9$, three per dosage group) received 5,10 , or $30 \mathrm{mg} / \mathrm{kg}$ BW fluoxetine per day orally for five consecutive days. Blood samples were collected 2 and $8 \mathrm{~h}$ after the first application, and then every $24 \mathrm{~h}$ after the daily application. Serum concentrations of fluoxetine and norfluoxetine were determined. Based on these results, we decided to treat the animals with $15 \mathrm{mg} / \mathrm{kg}$ BW fluoxetine per day, which resulted in a mean $( \pm$ SEM) plasma concentration of $380 \pm 111 \mathrm{ng} / \mathrm{ml}$ (range $81-634 \mathrm{ng}$ / $\mathrm{ml}$ ) of norfluoxetine $24 \mathrm{~h}$ after the last treatment of the 4-week treatment period; a similar range has been reported for patients under fluoxetine treatment (Baumann et al, 2004).

\section{Analysis of Fluoxetine}

Fluoxetine and its pharmacologically active metabolite norfluoxetine were determined in blood plasma using a high-performance liquid chromatography (HPLC) method with column switching and spectrophotometric detection, as described previously for the antipsychotic drug amisulpride (Sachse et al, 2003), with slight modifications. Serum $(0.1 \mathrm{ml})$ was injected into the HPLC system. For online sample clean-up on a column $(10 \times 4.0 \mathrm{~mm}$ i.d. $)$ filled with LiChrospher CN material of $20 \mu \mathrm{m}$ particle size (MZAnalysentechnik, Mainz, Germany), the column was washed with deionized water containing $8 \%(\mathrm{v} / \mathrm{v})$ acetonitrile to remove proteins and other interfering compounds. Drugs were eluted and separated on LiChrospher $\mathrm{CN}$ material ( $5 \mu \mathrm{m}$; column size $250 \times 4.6 \mathrm{~mm}$ i.d., MZ-Analysentechnik) using phosphate buffer ( $8 \mathrm{mM}, \mathrm{pH} 6.4)$ containing $500 \mathrm{ml} / \mathrm{l}$ acetonitrile, and were quantified by ultraviolet (UV) spectroscopy at $210 \mathrm{~nm}$. HPLC analysis was completed within $20 \mathrm{~min}$. Each analytical series included at least two control samples containing low $(50 \mathrm{ng} / \mathrm{ml})$ or high $(400 \mathrm{ng} /$ $\mathrm{ml}$ ) concentrations of fluoxetine and norfluoxetine, respectively. There was a linear correlation between drug concentration and UV signal from $10 \mathrm{ng} / \mathrm{ml}$ to at least $600 \mathrm{ng} / \mathrm{ml}$. The limit of quantification was $10 \mathrm{ng} / \mathrm{ml}$. Intraand interassay reproducibility of quality control samples was within $15 \%$.

\section{Perfusion and Brain Tissue Preparation}

Animals were anesthetized with an overdose of xylazine/ ketamine and perfused transcardially with $100 \mathrm{ml}$ of saline followed by $200 \mathrm{ml}$ of fixative containing $4 \% 0.1 \mathrm{M}$ sodium phosphate-buffered paraformaldehyde ( $\mathrm{pH} 7.4)$. The heads were postfixed in fresh fixative and, on the following day, the brains were gently removed from the skull. After cryoprotection with $0.1 \mathrm{M}$ phosphate-buffered saline (PBS; pH 7.4) containing $30 \%$ sucrose and $10 \%$ glycerol, a freezing microtome was used to collect serial horizontal 50$\mu \mathrm{m}$-thick sections throughout the dorsoventral extent of the left hippocampal formation. A stereotaxic brain atlas of the tree shrew (Tigges and Shantha, 1969) was used for reference during the cryosectioning procedures.

\section{GFAP Immunocytochemistry}

Samples from each treatment group were always processed in parallel to avoid any nonspecific effect of the staining procedure. Free-floating sections were washed in $0.1 \mathrm{M}$ PBS and then treated with $1 \% \mathrm{H}_{2} \mathrm{O}_{2}$ for 20 min. After washing, nonspecific binding of antibodies was prevented by incubating the sections for $1 \mathrm{~h}$ with $3 \%$ normal goat serum (NGS; Vector Laboratories, Burlingame, CA, USA) in $0.1 \mathrm{M}$ PBS containing $0.5 \%$ Triton X-100. The sections were subsequently incubated overnight with a mouse monoclonal antibody against GFAP (1:10000; Chemicon, Hofheim, Germany) at $4{ }^{\circ} \mathrm{C}$ in $0.1 \mathrm{M}$ PBS containing $0.5 \%$ Triton $\mathrm{X}-100$ and $1 \%$ NGS. The next day, the sections were rinsed several times in $0.1 \mathrm{M}$ PBS, incubated in a biotinylated mouse secondary antibody (1:200; Vector Laboratories, Burlingame, CA, USA) for $1 \mathrm{~h}$, rinsed, incubated in avidin-biotinhorseradish peroxidase $(1: 200$; Vectastaine Elite ABC Kit, Vector) for $1 \mathrm{~h}$, rinsed again, and developed for $5 \mathrm{~min}$ in diaminobenzidine $(1: 200$; DAB Peroxidase Substrate Kit, Vector), and then thoroughly rinsed. The sections were then mounted on glass slides in a $0.1 \%$ gelatin solution and dried overnight, after which they were dehydrated through stepped alcohol washes, cleared in xylene for $30 \mathrm{~min}$ and finally coverslipped under Eukitt.

\section{Stereological Estimates of Astrocyte Number and Size}

A single examiner who was blind to the group identification of each animal performed the data collection. After randomly selecting a starting point, every tenth section along the dorsoventral extent of the hippocampus was selected, yielding an average of 14 sections per animal for analysis. First, the boundaries of the hippocampal formation (hippocampus proper together with the dentate gyrus) were demarcated for the stereological analysis on the GFAPstained sections using a low power magnification lens $(\times 6.3,0.16 \mathrm{NA})$. The exact boundaries of the hippocampal formation in the tree shrew has been described in detail in an earlier study from our laboratory (Keuker et al, 2003), and these boundaries were easily recognizable in the GFAP stained sections as well. The total number $(N)$ of astrocytes was estimated with the optical disector following fractionator rules (Gundersen, 1998; West, 1999) and a semiautomated system (StereoInvestigator, version 4.04, Microbrightfield, Williston, VT, USA). Video images of GFAP-immunoreactive astrocytes were acquired with a $\times 100$ oil objective (1.3 NA) on a Zeiss III RS microscope (Carl Zeiss, Oberkochen, Germany) equipped with a CCD camera output to a high-resolution computer monitor and a Ludl X-Y-Z motorized stage (Ludl Electronics Products, Hawthorn, NY, USA). An astrocyte was counted only if it had a clearly defined nucleus within the disector area, did not intersect forbidden lines (Figure 1b), and came into focus as the optical plane moved through the height of the disector. After having counted all cells fulfilling the criteria 
of sampling, the total number of cells was estimated as:

$$
N_{\text {total }}=\Sigma Q^{-} \times 1 / \text { ssf } \times A(x, y \text { step }) / a(\text { frame }) \times t / h
$$

where $\Sigma Q^{-}$is the number of counted astrocytes; ssf is section sampling fraction $(1 / 10) ; A(x, y$ step) is the area associated with each $x, y$ movement (sampling area), which was $500 \mu \mathrm{m} \times 500 \mu \mathrm{m} ; a$ (frame) is the area of the counting frame, which was $50 \mu \mathrm{m} \times 50 \mu \mathrm{m} ; t$ is the thickness of the section $(24.3 \mu \mathrm{m})$; and $h$ is the height of the of the disector $(20 \mu \mathrm{m})$. The average postprocessing section thickness was $24.3 \mu \mathrm{m}$ and the guard height was $2 \mu \mathrm{m}$. Section thickness was determined in the hilus of each section by differential focusing using a $\times 100$ oil objective (1.3 NA). A single observer focused between the first and last sharp DABpositive profile (which were processes of the GFAP-positive astrocytes), while the vertical movement of the microscope stage was measured by the StereoInvestigator software (Microbrightfield). The precision of each cell number estimate was expressed as the coefficient of error (CE; Table 1).

The somal volume of the astrocyte cell body was calculated in every fifth counted glial cell using the nucleator probe (Möller et al, 1990, see Figure 1b).

\section{Determination of Hippocampal Volume}

Hippocampal volumes were assessed in the same sections as those used for counting astrocytes. The volumes were estimated according to the formula based on the Cavalieri principle (Gundersen et al, 1998):

$$
V=\Sigma A \times t_{\text {nom }} \times 1 / \text { ssf }
$$

where $\Sigma A$ is the cross-sectional hippocampal area, measured by tracing the borders of the hippocampus (Ammon's horn together with the dentate gyrus) using the StereoInvestigator 4.04 software; $t_{\text {nom }}$ is the nominal section thickness of $50 \mu \mathrm{m}$; and ssf is the sampling section fraction $(1 / 10)$.

\section{Adrenal and Testes Weight}

Increased adrenal and decreased testes weights are indicators of sustained stress exposure. Therefore, these organs were removed from the animal immediately after perfusion and weighed. Data are expressed in organ weight in milligrams per gram average body weight of the preceding week.

\section{Analysis of Serum Testosterone}

Before perfusing the animals, blood samples were collected. For determination of testosterone, $100 \mu \mathrm{l}$ serum was two times extracted with $1 \mathrm{ml}$ of diethylether by vortexing for $10 \mathrm{~min}$. Following extraction, the combined ether phases were evaporated under a stream of $\mathrm{N}_{2}$ and dried extracts reconstituted in $300 \mu \mathrm{l}$ assay buffer (PBS, containing $0.1 \%$ BSA, pH 7.0). Aliquots $(50 \mu \mathrm{l})$ of reconstituted extracts were then measured for concentrations of testosterone by

Table I Detailed Individual Figures of Astrocyte Number and Somal Volume

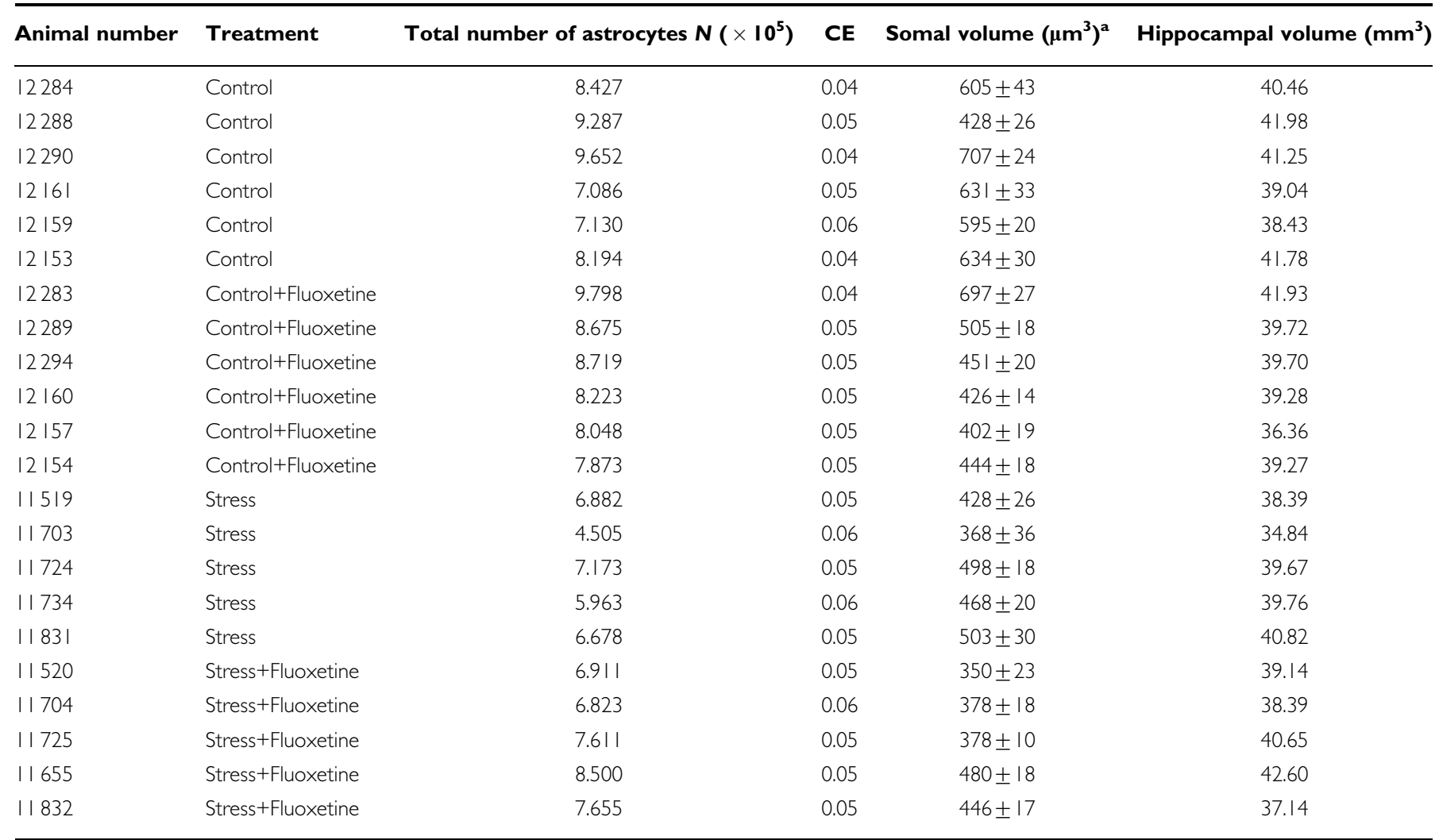

CE: coefficient of error, mean CE was calculated as $\sqrt{\text { mean }(C E)^{2}}$.

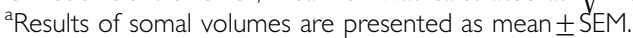


enzyme immunoassay, as described in detail by Kraus et al (1999).

\section{Statistical Analysis}

Results are expressed as the mean \pm SEM. Overall treatment effects were assessed with two-way analysis of variance (ANOVA, treatment $\times$ stress), followed by StudentNewman-Keuls post hoc analysis for further examination of group differences. Two-tailed Pearson test was used for correlation analysis.

\section{RESULTS}

Changes of Organ Weights and Serum Testosterone as an Indicator of Stress

Activation of the sympathoadrenomedullary system is an important and reliable indicator by which tree shrews can be classified as subordinates (Fuchs and Flugge, 2002). In animals from the Stress and Stress + Fluoxetine groups, adrenal weights were significantly increased (Figure 2a): two-way ANOVA (treatment $\times$ stress) revealed significant main effect of stress $(P=0.001)$, but not of treatment $(P=0.6)$. Moreover, we measured testes weights because gonadal hypotrophy is an indicator of sustained stress exposure (Fischer et al, 1985). Chronic stress exposure significantly reduced testes weight in the animals of the Stress and Stress + Fluoxetine groups (Figure 2b): two-way ANOVA (treatment $\times$ stress) revealed a highly significant main effect of stress $(P<0.001)$, but not of drug treatment $(P=0.2)$.

Not only testes weighs but serum testosterone concentrations were also significantly reduced by the repeated territorial conflict in the stressed animals, and this was not normalized by fluoxetine administration (Figure 2c). Two-way ANOVA (treatment $\times$ stress) revealed a significant main effect of stress $(P<0.01)$, but not of drug treatment $(P=0.5)$.

\section{Stereological Estimates of Astrocyte Number and Somal Volume}

Immunolabeling of the hippocampal formation for GFAP revealed numerous stellate structures distributed in a pattern similar to that observed in previous studies using rats (Schmidt-Kastner and Szymas, 1990). However, as shown in Figure 3, we observed a marked difference in GFAP staining intensity of the hippocampal tissue between control (Control, Control + Fluoxetine) and stressed animals (Stress and Stress + Fluoxetine).

Stereological estimates showed that exposure to chronic stress significantly decreased the total number of GFAPimmunoreactive cells by $25 \%$ (Figure $4 \mathrm{a}$, Table 1). Two-way ANOVA (treatment $\times$ stress) revealed a highly significant main effect of stress $(P<0.001)$, and the effect of fluoxetine treatment was close to the level of significance $(P=0.06)$. Student-Newman-Keuls post hoc comparisons showed a significant difference between the Control and Stress groups $(q=5.35, P<0.01)$. Treatment of stressed animals with fluoxetine offered protection from the effects of stress, resulting in an almost complete preservation of GFAP-
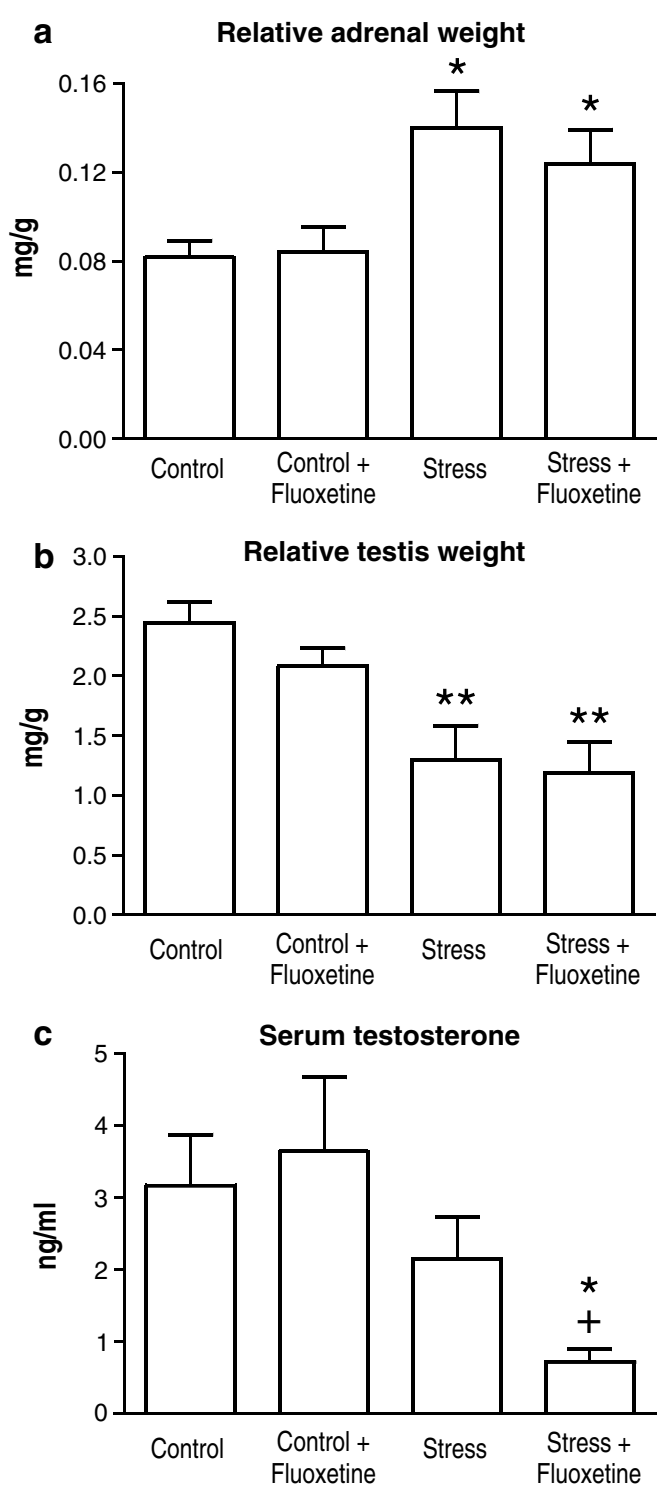

Figure 2 The physiological consequences of the repeated territorial conflict were expressed in the significant changes in relative organ weights and testosterone concentrations. Stress significantly increased relative adrenal weights (a), and reduced relative testes weights (b) and serum testosterone concentrations (c). Results are given as organ weight in milligrams per gram average body weight during the last experimental week (mean \pm SEM). Serum testosterone levels were measured from blood samples collected before perfusing the animals, and presented here in nanograms testosterone per milliliter serum (mean \pm SEM). Statistics: Twoway ANOVA followed by Student-Newman-Keuls post hoc analysis. ${ }^{*} P<0.05$, ${ }^{*} * P<0.0$ I vs Control, ${ }^{+} P<0.05$ vs Contrtol + Fluoxetine.

immunoreactive astroglia and a statistically significant difference was revealed when the Stress + Fluoxetine group was compared with the Stress group $(q=3.14, P<0.05)$. In contrast, no difference was found between the Stress + Fluoxetine group and controls $(P=0.6)$. In control animals, fluoxetine treatment alone had no effect on GFAP-positive astrocyte numbers (Figure $4 \mathrm{a}$, Table 1).

Cell bodies immunopositive for GFAP were significantly decreased both by chronic stress and by fluoxetine treatment (Figure 4b, Table 1). Two-way ANOVA (treatment $\times$ stress) revealed a significant main effect both of 


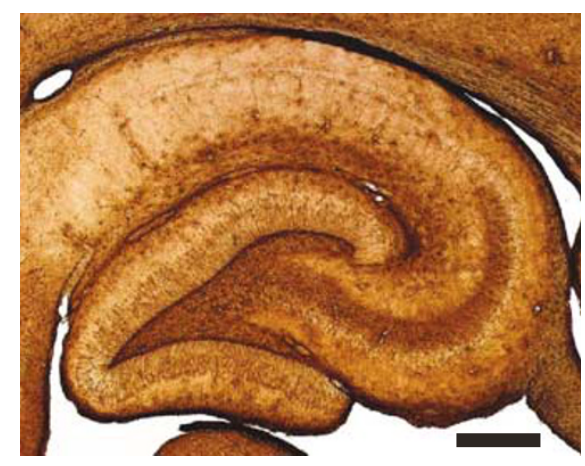

Control

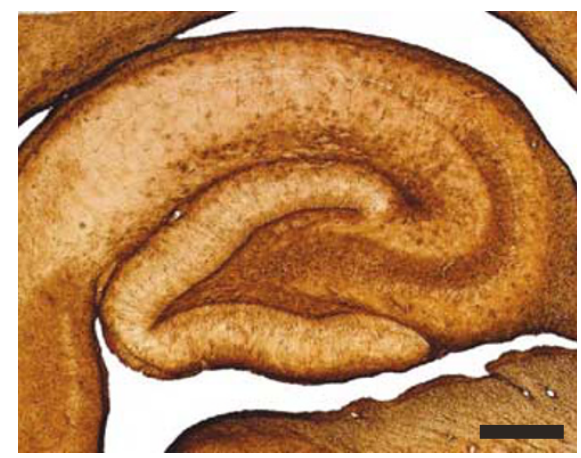

Control + Fluoxetine

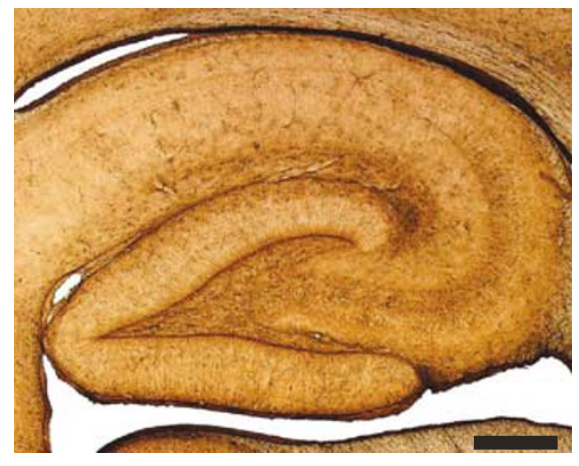

Stress

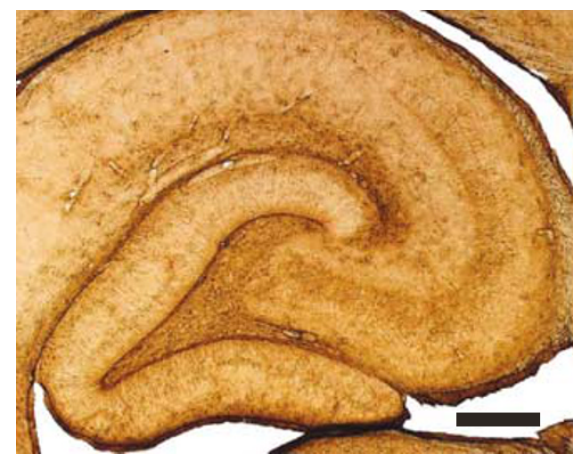

Stress + Fluoxetine

Figure 3 Representative examples of a glial fibrillary acidic protein (GFAP) stained horizontal section of the tree shrew hippocampal formation. Note the marked difference in GFAP staining intensity between the control (Control, Control + Fluoxetine) and stressed groups (Stress and Stress + Fluoxetine). Scale bars, $500 \mu \mathrm{m}$.

stress $(P<0.01)$ and of fluoxetine treatment $(P<0.05)$. Student-Newman-Keuls post hoc comparisons showed significant differences between the Control and Stress groups $(q=4.10, P<0.05)$, between the Control and Stress + Fluoxetine groups $(q=5.40, P<0.01)$, and between the Control and Control + Fluoxetine groups $(q=3.29$, $P<0.05)$, see Figure $4 \mathrm{~b}$.

\section{Hippocampal Volume}

A mild decrease $(-5 \%)$ of hippocampal volume was observed in the chronically stressed animals, but neither stress nor fluoxetine treatment had a statistically significant effect on hippocampal volume (Figure 5a). Interestingly, correlation analysis revealed significant correlations between the hippocampal volume and the total number of astrocytes (Pearson $r=0.6528, \quad P=0.001$ ), as well as between hippocampal volume and the somal volumes of the astrocytes (Pearson $r=0.4828, P<0.05$ ) (Figure $5 \mathrm{~b}$ and c).

\section{DISCUSSION}

To our knowledge, this study is the first to examine numerical and morphological changes of astrocytes after long-term psychosocial stress and antidepressant treatment. We demonstrated that chronic psychosocial conflict can result in significantly fewer astroglia, and concomitant treatment with fluoxetine can block this effect of long-term stress. Both chronic stress and fluoxetine treatment reduced the somal volumes of astrocytes; moreover, this treatment's effect was additive. Furthermore, we found that hippocampal volume correlated with the number and somal size of astrocytes.

\section{Effect of Stress and Fluoxetine Treatment on the Endocrine System}

Chronic psychosocial stress activates the hypothalamicpituitary adrenal (HPA) system, increases the neurosympathetic tone, and suppresses gonadal activity. As demonstrated in previous studies (Fuchs and Flugge, 2002), repeated confrontations significantly increased the adrenal weights, but in contrast reduced testis weights and serum testosterone concentrations. Similar to earlier findings, fluoxetine administration did not influence these organ weight changes and had no effect on serum testosterone levels (Taylor et al, 1996).

\section{Structural Changes of Astrocytes - Implication for Psychiatry}

Abnormalities of glial function are likely to contribute to the impairments of structural plasticity and overall pathophysiology of mood disorders (Coyle and Schwarcz, 2000; Cotter et al, 2001b; Manji et al, 2003; Fuchs et al, 2004). A number of post-mortem histological analyses demonstrated a decreased number of glia in specific areas of the prefrontal, orbitofrontal, and cingulate cortex (Öngür 

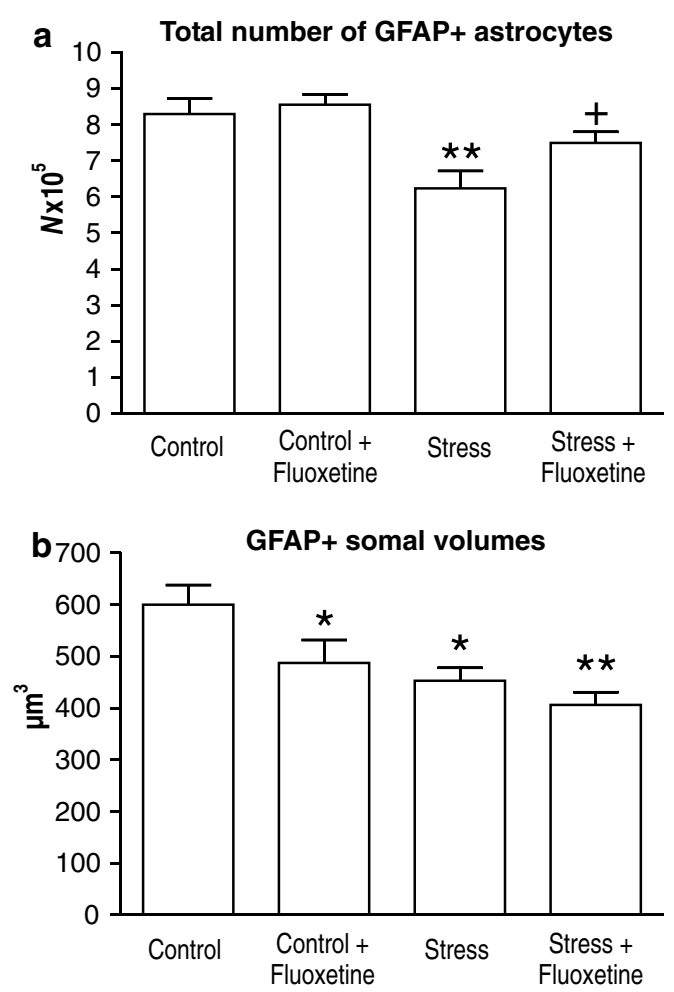

Figure 4 Effects of chronic psychosocial stress and concomitant fluoxetine treatment on the total number of GFAP-immunoreactive astrocytes in the hippocampal formation (a) and on the somal volumes of these GFAP-positive cells (b). (a) Stress significantly decreased the number of GFAP-IR astrocytes, whereas fluoxetine treatment resulted in a partial normalization of GFAP-positive glial numbers. Results are given as mean total numbers $\left(\times 10^{5}\right) \pm$ SEM. (b) Somal volumes were significantly reduced by both stress and fluoxetine treatment. Results are presented as mean somal volume (cubic micrometers) \pm SEM. Statistics: Two-way ANOVA followed by Student-Newman-Keuls post hoc analysis. $* P<0.05$, ${ }^{*} * P<0.0$ I vs Control; ${ }^{+} P<0.05$ vs Stress.

et al, 1998; Rajkowska et al, 1999; Cotter et al, 2001a, 2002; Miguel-Hidalgo and Rajkowska, 2002), and in the amygdala of depressed patients (Bowley et al, 2002; Hamidi et al, 2004). Despite the in vivo documented hippocampal volume reduction in patients suffering from depression, postmortem histopathological analysis so far has not revealed any significant reduction of neuronal or glial cells in hippocampal samples from patients (Lucassen et al, 2001; Müller et al, 2001; Stockmeier et al, 2004). However, reduced GFAP staining was reported in the hippocampi of steroid-treated and depressed patients (Müller et al, 2001). It should be noted that, in most of these clinical studies, the depressed patients were not free of antidepressant medication, and our present results indicate this could be a confounding factor. Furthermore, all of these studies examined only a few sections from the hippocampal formation, and thus these negative findings might be due to the small sample size. Future and more systematic studies that examine the entire structure will be able to answer the question of possible changes in neuronal/glial cell numbers in the hippocampus of depressed patients. It might also be the case that anatomical examinations should focus on specific subpopulation of neuronal/glial cells, as we did in this study, to reveal changes in cell number. This is
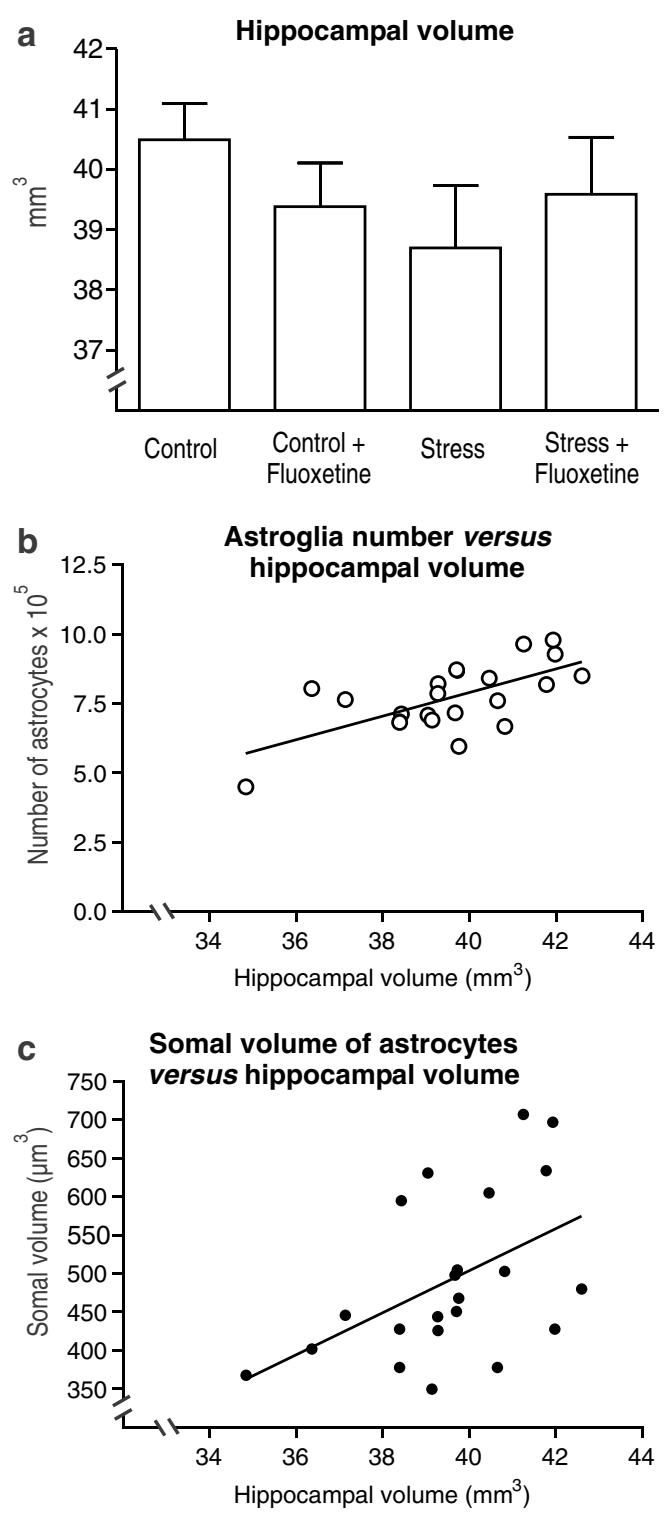

Figure 5 (a) There was a minor (-5\%) nonsignificant decrease of the hippocampal volume in the Stress group, but neither stress nor drug treatment had a statistically significant effect on hippocampal volume. (b and c) Correlation analysis revealed that individual hippocampal volumes significantly correlated both with the total number of astrocytes $(r=0.65$, $P=0.00 \mathrm{I})$, as well as the somal volumes of the astrocytes $(r=0.48$, $P<0.05)$.

important, because there might be a significant reduction in the number of a certain type of cells, for example, specific interneurons or particular glial cell types. One has to consider that this numerical change-which affects only the portion of the cells - is not great enough to yield a significant change in the overall number of neurons or glial cells.

Using a chronic psychosocial stress paradigm, we found a significantly reduced number of astroglia in response to stress. More importantly, this stress effect was prevented by concomitant antidepressant treatment. The fact that the number of GFAP-labeled astroglia was not affected by treatment with fluoxetine in nonstressed animals suggests that the effects of stress were blocked by the SSRI and not 
vice versa. These findings support current theories proposing that stress-related disorders such as major depression may be associated with an impairment of structural plasticity, and that antidepressants may act by correcting this dysfunction (Manji et al, 2003).

\section{Functional Consequences}

Recent studies have revealed that, beside their housekeeping functions, astrocytes are dynamic regulators of synaptogenesis and synaptic strength and control neuronal production in the adult dentate gyrus (Goldman, 2003; Horner and Palmer, 2003; Nedergaard et al, 2003; Newman, 2003; Slezak and Pfrieger, 2003). Morphological changes of the astrocytes must have functional significance on the neuron-glia and finally on neuron-neuron communication. The reduced number or weakened activity of astrocytes may lead to impairment reducing the levels of extracellular glutamate, and this may result in too much glutamate in the synaptic cleft, and in consequence to excitotoxic cell damage. Upregulation of the glial glutamate transporter (GLT-1) in the hippocampus has been reported after chronic stress, and it has been suggested that this might be a compensatory mechanism to control the increased extracellular concentrations of glutamate observed during stress. Interestingly, antidepressant treatment with tianeptine can block the stress-induced upregulation of GLT-1 (Reagan et al, 2004).

Another possible mechanism by which the altered activity of astrocytes can induce functional impairments of neuronal activity is the production of neurotrophic factors. Astrocytes synthesize and release many neurotrophic factors vital for neuronal health such as brain-derived neurotrophic factor (BDNF), glial-derived neurotrophic factor (GDNF), nerve growth factor (NGF), and neurotrophins 3 and 4/5 (Friedman et al, 1998; Althaus and RichterLandsberg, 2000). These neurotrophic factors regulate neuronal growth, maintenance, and plasticity, and their reduced availability can result in increased cellular vulnerability or even cell death. Stress can reduce the expression of BDNF in the hippocampus, which in turn can be prevented by long-term chronic antidepressant treatment (reviewed by Duman et al, 1997; Russo-Neustadt and Chen, 2005). It is likely that astrocytes contribute to the enhancement in neurotrophic support and associated augmentation in synaptic plasticity that may form the basis for antidepressant efficacy.

\section{Effect of Fluoxetine Treatment on Astroglial Plasticity}

Recently, several groups proposed that glial cells should receive much greater attention when we attempt to understand the underlying biological mechanisms of psychiatric disorders, or the action of antidepressant therapy (Coyle and Schwarcz, 2000; Cotter et al, 2001b; Öngür and Heckers, 2004). The exact cellular mechanism by which fluoxetine exerts its therapeutic effect is not fully understood; its curative effect is attributed to its capacity to inhibit the neuronal reuptake of serotonin. However, fluoxetine exerts a direct effect on astrocytes as well (Chen et al, 1995; Kong et $a l, 2002)$ and this mechanism cannot be ignored when attempting to elucidate its mechanisms of action. Astrocytes, as part of the blood-brain barrier, form close connections with capillaries and thus are the primary target of any molecule entering the brain. In mammals, astrocytes can take up serotonin by a sodium-dependent, high affinity system (Kimelberg and Katz, 1985) and they express several different 5-HT receptor subtypes, for example, 5- $\mathrm{HT}_{1 \mathrm{~A}}$, $5-\mathrm{HT}_{2 \mathrm{~A}}$ (Azmitia, 2001; Azmitia et al, 1996). Especially the $5-\mathrm{HT}_{1 \mathrm{~A}}$ receptors, activation of which is suggested to be a critical component in the mechanism of action of SSRIs (Santarelli et al, 2003), occur in high abundance on hippocampal astroglia (Azmitia et al, 1996).

There are a few reports that beside fluoxetine, other drugs can also modulate the structural plasticity of astrocytes. After chronic lithium and antipsychotic medication, increased numbers of glia have been reported in the hippocampus and prefrontal cortex of rats and nonhuman primates (Rocha et al, 1998; Selemon et al, 1999). In contrast to that in our study, fluoxetine had no effect on hippocampal astrocyte numbers in control animals, but could counteract the stress-induced decrease of astrocyte numbers. Chronic treatment with lithium upregulates GFAP expression and modifies the morphology (orientation) of astrocytes (Rocha and Rodnight, 1994; Rocha et $a l, 1998)$. We report here that fluoxetine can reduce the somal volumes of astrocytes. Altogether our data demonstrate that fluoxetine, a prominent member of the SSRI family (Hiemke and Härtter, 2000), can significantly modify the structural plasticity of astrocytes, and it is very likely that these morphological alterations either reflect or induce functional changes within the glial-neuronal interaction.

\section{Morphological Changes of Astroglia may Contribute to Hippocampal Volume Decrease}

Recent imaging studies in humans revealed that the hippocampus undergoes selective volume reduction in several stress-related psychiatric illnesses such as major depressive disorder (reviewed by Manji and Duman, 2001; Manji et al, 2003; Bremner, 2002; Drevets, 2000; Sheline, 2003). Similar findings have been reported in animals submitted to chronic stress (Ohl et al, 2000; van der Hart et al, 2002; Alonso et al, 2004; Czéh et al, 2005a). The exact mechanisms responsible for this hippocampal volume loss have not yet been identified. Massive neuronal loss following exposure to repeated episodes of hypercortisolemia can be excluded, because, in human post-mortem brain tissue of severely depressed patients or of steroid hormone treated human or nonhuman primate subjects, no major cell loss was apparent, nor was any neuropathology present (Leverenz et al, 1999; Lucassen et al, 2001; Müller et al, 2001; Stockmeier et al, 2004). This is consistent with findings of preclinical studies that failed to reveal any loss of principal neurons in the hippocampal formation after chronic stress exposure (Vollmann-Honsdorf et al, 1997; Sousa et al, 1998; Keuker et al, 2001). Stress-induced dendritic retraction of CA3 pyramidal neurons and suppression of dentate neurogenesis have been implicated as mechanisms contributing to hippocampal shrinkage (McEwen, 2000). In the present study we found that the hippocampal volume correlated both with the total number of astrocytes as well as their somal volumes. Based on the present findings, it appears that the stress-induced reduc- 
tion of astroglia number and size can contribute to the hippocampal volume changes.

\section{Limitations of the Study}

There are certain limitations to our study that should be kept in mind when interpreting these data. First, the visualization of astrocyte morphology by immunostaining for cytoskeletal proteins, such as GFAP, delineates only about $15 \%$ of the cell's total volume (Bushong et al, 2002). Because of this limitation of the labeling technique, it is probable that the somal volume values reported here do not reflect the real somal volumes; however, it is unlikely that this could significantly influence the results of the comparisons between the groups. Our experiment does not answer the question whether the stress-induced decrease of astrocytic cell number represents true cell loss, or is due to expression of the cytoskeletal GFAP protein being downregulated to a level undetectable by immunohistochemistry. Note that the GFAP staining intensity was markedly reduced in the stressed animals (see Figure 3). Stressed tree shrews have significantly increased cortisol levels (Fuchs and Flugge, 2002) and it is well known that glucocorticoids can reduce GFAP mRNA and protein expression in the hippocampus (Laping et al, 1994). Further animal studies are required to determine whether other stress paradigms and other types of antidepressant have similar effects on astrocytes in the hippocampus and prefrontal brain areas in order elucidate results from human studies.

\section{CONCLUSION}

The pronounced astroglial structural plasticity as a result of chronic psychosocial stress and the antagonizing effects by fluoxetine treatment provides further support for the notion that glial changes may contribute to the pathophysiology of stress-related disorders as well as to the biological actions of antidepressants.

\section{ACKNOWLEDGEMENTS}

This study was partially supported by GlaxoSmithKline, Verona, Italy. We thank S Donath and A Heutz for their excellent technical assistance and S Heller and A RiegerGies for the analysis of fluoxetine and norfluoxetine. B Czéh is supported by the DFG Research Center Molecular Physiology of the Brain (CMPB).

\section{REFERENCES}

Alonso R, Griebel G, Pavone G, Stemmelin J, Le Fur G, Soubrie P (2004). Blockade of $\mathrm{CRF}(1)$ or $\mathrm{V}(1 \mathrm{~b})$ receptors reverses stressinduced suppression of neurogenesis in a mouse model of depression. Mol Psychiatry 9: 278-286.

Althaus HH, Richter-Landsberg C (2000). Glial cells as targets and producers of neurotrophins. Int Rev Cytol 197: 203-277.

Azmitia EC (2001). Modern views on an ancient chemical: serotonin effects on cell proliferation, maturation, and apoptosis. Brain Res Bull 56: 413-424.

Azmitia EC, Gannon PJ, Kheck NM, Whitaker-Azmitia PM (1996). Cellular localization of the 5-HT1A receptor in primate brain neurons and glial cells. Neuropsychopharmacology 14: 35-46.

Baumann P, Hiemke C, Ulrich S, Eckermann G, Gaertner I, Gerlach $M$ et al (2004). The AGNP-TDM Expert Group Consensus Guidelines: therapeutic drug monitoring in psychiatry. Pharmacopsychiatry 37: 243-265.

Bowley MP, Drevets WC, Ongur D, Price JL (2002). Low glial numbers in the amygdala in major depressive disorder. Biol Psychiatry 52: 404-412.

Bremner JD (2002). Neuroimaging studies in post-traumatic stress disorder. Curr Psychiatry Rep 4: 254-263.

Brown G (1993). Life events and illness. In: Stanford SC, Salamon P (eds). Stress: From Synapse to Syndrome. Academic Press: London. pp 20-40.

Bushong EA, Martone ME, Jones YZ, Ellisman MH (2002). Protoplasmic astrocytes in CA1 stratum radiatum occupy separate anatomical domains. J Neurosci 22: 183-192.

Chen Y, Peng L, Zhang X, Stolzenburg JU, Hertz L (1995). Further evidence that fluoxetine interacts with a 5-HT2C receptor in glial cells. Brain Res Bull 38: 153-159.

Cotter D, Mackay D, Chana G, Beasley C, Landau S, Everall IP (2002). Reduced neuronal size and glial cell density in area 9 of the dorsolateral prefrontal cortex in subjects with major depressive disorder. Cereb Cortex 12: 386-394.

Cotter D, Mackay D, Landau S, Kerwin R, Everall I (2001a). Reduced glial cell density and neuronal size in the anterior cingulate cortex in major depressive disorder. Arch Gen Psychiatry 58: 545-553.

Cotter DR, Pariante CM, Everall IP (2001b). Glial cell abnormalities in major psychiatric disorders: the evidence and implications. Brain Res Bull 55: 585-595.

Coyle JT, Schwarcz R (2000). Mind glue: implications of glial cell biology for psychiatry. Arch Gen Psychiatry 57: 90-93.

Czéh B, Michaelis T, Watanabe T, Frahm J, de Biurrun G, van Kampen $\mathrm{M}$ et al (2001). Stress-induced changes in cerebral metabolites, hippocampal volume, and cell proliferation are prevented by antidepressant treatment with tianeptine. Proc Natl Acad Sci USA 98: 12796-12801.

Czéh B, Pudovkina O, van der Hart MG, Simon M, Heilbronner U, Michaelis $\mathrm{T}$ et al (2005a). Examining SLV-323, a novel NK1 receptor antagonist, in a chronic psychosocial stress model for depression. Psychopharmacology (Berl) 180: 548-557.

Czéh B, Simon M, van der Hart MG, Schmelting B, Hesselink MB, Fuchs E (2005b). Chronic stress decreases the number of parvalbumin-immunoreactive interneurons in the hippocampus: prevention by treatment with a substance $\mathrm{P}$ receptor (NK1) antagonist. Neuropsychopharmacology 30: 67-79.

Drevets WC (2000). Functional anatomical abnormalities in limbic and prefrontal cortical structures in major depression. Prog Brain Res 126: 413-431.

Duman RS, Heninger GR, Nestler EJ (1997). A molecular and cellular theory of depression. Arch Gen Psychiatry 54: 597-606.

Fields RD, Stevens-Graham B (2002). New insights into neuronglia communication. Science 298: 556-562.

Fischer HD, Heinzeller T, Raab A (1985). Gonadal response to psychosocial stress in male tree shrews (Tupaia belangeri) morphometry of testis, epididymis and prostate. Andrologia 17: 262-275.

Friedman WJ, Black IB, Kaplan DR (1998). Distribution of the neurotrophins brain-derived neurotrophic factor, neurotrophin-3, and neurotrophin-4/5 in the postnatal rat brain: an immunocytochemical study. Neuroscience 84: 101-114.

Fuchs E (1999). Tree Shrews. In: Poole T (ed). UFAW Handbook on the Care and Management of Laboratory Animals, 7th edn. Blackwell: Oxford, UK. pp 235-245.

Fuchs E, Czeh B, Kole MH, Michaelis T, Lucassen PJ (2004). Alterations of neuroplasticity in depression: the hippocampus and beyond. Eur Neuropsychopharmacol 14(Suppl 5): S481-S490. 
Fuchs E, Flugge G (2002). Social stress in tree shrews: effects on physiology, brain function, and behavior of subordinate individuals. Pharmacol Biochem Behav 73: 247-258.

Goldman S (2003). Glia as neural progenitor cells. Trends Neurosci 26: $590-596$.

Gundersen HJ, Bagger P, Bendtsen TF, Evans SM, Korbo L, Marcussen $\mathrm{N}$ et al (1988). The new stereological tools: disector, fractionator, nucleator and point sampled intercepts and their use in pathological research and diagnosis. APMIS 96: 857-881.

Hamidi M, Drevets WC, Price JL (2004). Glial reduction in amygdala in major depressive disorder is due to oligodendrocytes. Biol Psychiatry 55: 563-569.

Hiemke C, Härtter S (2000). Pharmacokinetic of selective serotonin reuptake inhibitors. Pharmacol Therap 85: 11-28.

Horner PJ, Palmer TD (2003). New roles for astrocytes: the nightlife of an 'astrocyte' La vida loca!. Trends Neurosci 26: 597-603.

Kendler KS, Karkowski LM, Prescott CA (1999). Causal relationship between stressful life events and the onset of major depression. Am J Psychiatry 156: 837-841.

Keuker JI, Rochford CD, Witter MP, Fuchs E (2003). A cytoarchitectonic study of the hippocampal formation of the tree shrew (Tupaia belangeri). J Chem Neuroanat 26: 1-15.

Keuker JI, Vollmann-Honsdorf GK, Fuchs E (2001). How to use the optical fractionator: an example based on the estimation of neurons in the hippocampal CA1 and CA3 regions of tree shrews. Brain Res Brain Res Protoc 7: 211-221.

Kimelberg HK, Katz DM (1985). High-affinity uptake of serotonin into immunocytochemically identified astrocytes. Science 228: 889-891.

Kong EK, Peng L, Chen Y, Yu AC, Hertz L (2002). Up-regulation of 5-HT2B receptor density and receptor-mediated glycogenolysis in mouse astrocytes by long-term fluoxetine administration. Neurochem Res 27: 113-120.

Kraus C, Heistermann M, Kappeler PM (1999). Physiological suppression of sexual function of subordinate males: a subtle form of intrasexual competition among male sifakas (Propithecus verreauxi)? Physiol Behav 66: 855-861.

Laping NJ, Teter B, Nichols NR, Rozovsky I, Finch CE (1994). Glial fibrillary acidic protein: regulation by hormones, cytokines, and growth factors. Brain Pathol 4: 259-275.

Leverenz JB, Wilkinson CW, Wamble M, Corbin S, Grabber JE, Raskind MA et al (1999). Effect of chronic high-dose exogenous cortisol on hippocampal neuronal number in aged nonhuman primates. J Neurosci 19: 2356-2361.

Lucassen PJ, Fuchs E, Czeh B (2004). Antidepressant treatment with tianeptine reduces apoptosis in the hippocampal dentate gyrus and temporal cortex. Biol Psychiatry 55: 789-796.

Lucassen PJ, Muller MB, Holsboer F, Bauer J, Holtrop A, Wouda J et al (2001). Hippocampal apoptosis in major depression is a minor event and absent from subareas at risk for glucocorticoid overexposure. Am J Pathol 158: 453-468.

Malberg JE, Duman RS (2003). Cell proliferation in adult hippocampus is decreased by inescapable stress: reversal by fluoxetine treatment. Neuropsychopharmacology 28: 1562-1571.

Manji HK, Drevets WC, Charney DS (2001). The cellular neurobiology of depression. Nat Med 7: 541-547.

Manji HK, Duman RS (2001). Impairments of neuroplasticity and cellular resilience in severe mood disorders: implications for the development of novel therapeutics. Psychopharmacol Bull 35: 5-49.

Manji HK, Moore GJ, Rajkowska G, Chen G (2000). Neuroplasticity and cellular resilience in mood disorders. Mol Psychiatry 5: 578-593.

Manji HK, Quiroz JA, Sporn J, Payne JL, Denicoff K, A Gray N et al (2003). Enhancing neuronal plasticity and cellular resilience to develop novel, improved therapeutics for difficult-to-treat depression. Biol Psychiatry 53: 707-742.
Martin RD (1990). Are tree shrews primates? In: Martin RD (ed). Primate Origins and Evolution. Chapman \& Hall: London, UK. pp 191-213.

McEwen BS (2000). The neurobiology of stress: from serendipity to clinical relevance. Brain Res 886: 172-189.

Miguel-Hidalgo JJ, Rajkowska G (2002). Morphological brain changes in depression: can antidepressants reverse them? CNS Drugs 16: 361-372.

Möller A, Strange P, Gundersen HJ (1990). Efficient estimation of cell volume and number using the nucleator and the disector. J Microsc 159: 61-71.

Müller MB, Lucassen PJ, Yassouridis A, Hoogendijk WJ, Holsboer F, Swaab DF (2001). Neither major depression nor glucocorticoid treatment affects the cellular integrity of the human hippocampus. Eur J Neurosci 14: 1603-1612.

Nedergaard M, Ransom B, Goldman SA (2003). New roles for astrocytes: redefining the functional architecture of the brain. Trends Neurosci 26: 523-530.

Nestler EJ, Barrot M, DiLeone RJ, Eisch AJ, Gold SJ, Monteggia LM (2002). Neurobiology of depression. Neuron 34: 13-25.

Newman EA (2003). New roles for astrocytes: regulation of synaptic transmission. Trends Neurosci 26: 536-542.

Ohl F, Michaelis T, Vollmann-Honsdorf GK, Kirschbaum C, Fuchs E (2000). Effect of chronic psychosocial stress and long-term cortisol treatment on hippocampus-mediated memory and hippocampal volume: a pilot-study in tree shrews. Psychoneuroendocrinology 25: 357-363.

Öngür D, Drevets WC, Price JL (1998). Glial reduction in the subgenual prefrontal cortex in mood disorders. Proc Natl Acad Sci USA 95: 13290-13295.

Öngür D, Heckers S (2004). A role for glia in the action of electroconvulsive therapy. Harv Rev Psychiatry 12: 253-262.

Rajkowska G, Miguel-Hidalgo JJ, Wei J, Dilley G, Pittman SD, Meltzer HY et al (1999). Morphometric evidence for neuronal and glial prefrontal cell pathology in major depression. Biol Psychiatry 45: 1085-1098.

Reagan LP, Rosell DR, Wood GE, Spedding M, Munoz C, Rothstein $\mathrm{J}$ et al (2004). Chronic restraint stress up-regulates GLT-1 mRNA and protein expression in the rat hippocampus: reversal by tianeptine. Proc Natl Acad Sci USA 101: 2179-2184.

Rocha E, Achaval M, Santos P, Rodnight R (1998). Lithium treatment causes gliosis and modifies the morphology of hippocampal astrocytes in rats. Neuroreport 9: 3971-3974.

Rocha E, Rodnight R (1994). Chronic administration of lithium chloride increases immunodetectable glial fibrillary acidic protein in the rat hippocampus. J Neurochem 63: 1582-1584.

Russo-Neustadt AA, Chen MJ (2005). Brain-derived neurotrophic factor and antidepressant activity. Curr Pharm Des 11: $1495-1510$.

Sachse J, Hartter S, Weigmann H, Hiemke C (2003). Automated determination of amisulpride by liquid chromatography with column switching and spectrophotometric detection. J Chromatogr B Anal Technol Biomed Life Sci 784: 405-410.

Santarelli L, Saxe M, Gross C, Surget A, Battaglia F, Dulawa S et al (2003). Requirement of hippocampal neurogenesis for the behavioral effects of antidepressants. Science 301: 805-809.

Schmidt-Kastner R, Szymas J (1990). Immunohistochemistry of glial fibrillary acidic protein, vimentin and S-100 protein for study of astrocytes in hippocampus of rat. J Chem Neuroanat 3: 179-192.

Selemon LD, Lidow MS, Goldman-Rakic PS (1999). Increased volume and glial density in primate prefrontal cortex associated with chronic antipsychotic drug exposure. Biol Psychiatry 46: 161-172.

Sheline YI (2003). Neuroimaging studies of mood disorder effects on the brain. Biol Psychiatry 54: 338-352.

Slezak M, Pfrieger FW (2003). New roles for astrocytes: regulation of CNS synaptogenesis. Trends Neurosci 26: 531-535. 
Sousa N, Almeida OF, Holsboer F, Paula-Barbosa MM, Madeira MD (1998). Maintenance of hippocampal cell numbers in young and aged rats submitted to chronic unpredictable stress. Comparison with the effects of corticosterone treatment. Stress 2: 237-249.

Stockmeier CA, Mahajan GJ, Konick LC, Overholser JC, Jurjus GJ, Meltzer HY et al (2004). Cellular changes in the postmortem hippocampus in major depression. Biol Psychiatry 56: 640-650.

Stokes PE, Holtz A (1997). Fluoxetine tenth anniversary update: the progress continues. Clin Ther 19: 1135-1250.

Taylor G, Bardgett M, Csernansky J, Early T, Haller J, Scherrer J, Womack S (1996). Male reproductive systems under chronic fluoxetine or trimipramine treatment. Physiol Behav 59: 479-485.

Tigges J, Shantha TR (1969). A Stereotaxic Brain Atlas of the Tree Shrew (Tupaia glis). Waverly Press: Baltimore, MD.

van der Hart MG, Czeh B, de Biurrun G, Michaelis T, Watanabe T, Natt $\mathrm{O}$ et al (2002). Substance $\mathrm{P}$ receptor antagonist and clomipramine prevent stress-induced alterations in cerebral metabolites, cytogenesis in the dentate gyrus and hippocampal volume. Mol Psychiatry 7: 933-941.

Vermetten E, Vythilingam M, Southwick SM, Charney DS, Bremner JD (2003). Long-term treatment with paroxetine increases verbal declarative memory and hippocampal volume in posttraumatic stress disorder. Biol Psychiatry 54: 693-702.

Vollmann-Honsdorf GK, Flugge G, Fuchs E (1997). Chronic psychosocial stress does not affect the number of pyramidal neurons in tree shrew hippocampus. Neurosci Lett 233: 121-124.

Watanabe Y, Gould E, Daniels DC, Cameron H, McEwen BS (1992). Tianeptine attenuates stress-induced morphological changes in the hippocampus. Eur J Pharmacol 222: 157-162.

West MJ (1999). Stereological methods for estimating the total number of neurons and synapses: issues of precision and bias. Trends Neurosci 22: 51-61. 